\title{
Familial cerebellar ataxia and hypogonadotropic hypogonadism: evidence for hypothalamic LHRH deficiency
}

\author{
J BERCIANO, JA AMADO, J FREIJANES, M REBOLLO, A VAQUERO \\ From the Sections of Neurology and Endocrinology, Centro Médico Nacional "Marqués de Valdecilla", \\ Santander, Spain
}

SUMMARY A family with familial cerebellar ataxia and hypogonadotropic hypogonadism is described. The condition was inherited as an autosomal recessive defect. CT scan in one case revealed cerebellar and brain stem atrophy. Endocrinological tests showed abnormalities only in two patients who were clinically affected. In both cases raised gonadotropic levels were found after repetitive stimulation with luteining hormone-releasing hormone which suggests that the hypogonadism was due to a primary hypothalamic disturbance.

Familial cerebellar ataxia and hypogonadism is a rare disorder in which spinocerebellar atrophy is accompanied by hypogonadotrophic hypogonadism. ${ }^{1-3}$ In the cases previously reported, the diagnosis of hypogonadotropic hypogonadism was based on low levels of urinary gonadotropins. ${ }^{1-6}$ A hypothalamic origin for this hypogonadism was postulated, ${ }^{15}$ but not demonstrated. The investigations carried out on the family reported here suggest a hypothalamic LHRH deficiency.

\section{Case reports}

The pedigree (fig (A)) of the family involved in the study showed obvious consanguinity between the parents of the affected individuals. No abnormalities were found on clinical examination of cases V-5, V-6, VI-5, VI-6, VI-8, VI-9 and VI-11.

Case VI-10 A 34-year-old female, married, with no children. At the age 20 years, the patient had been treated for primary amenorrhoea and absence of secondary sexual characteristics. Since then sequential therapy had been

Address for reprint requests: Dr José Berciano, Sección de Neurologia, Centro Médico Nacional "Marqués de Valdecilla", Santander, Spain.

Received 2 August 1981 and in revised form 19 December 1981 Accepted 22 March 1982 given with mestranol $80 \mathrm{mcg}$ and mestranol $80 \mathrm{mcg}$ plus chlormadinone acetate $20 \mathrm{mcg}$, and regular menstruation had been achieved. Neurological problems had started at 19 years with dysarthria. Since the age of 30 years, unstable gait, intention tremor and urinary incontinence had occurred. On examination, the patient was cooperative with no signs of dementia, but there was marked limb and axial ataxia, with scanning dysarthria and generalised hypotonia. Muscle-stretch reflexes were enhanced symmetrically; plantar responses were flexor. Sensitivity to pain and proprioceptive sensation were diminished distally in all four limbs. There was bilateral pes cavus, but no other motor deficit, amyotrophy, scoliosis or nystagmus were observed. Cranial nerve testing was normal. The development of secondary sexual characteristics was normal.

Routine blood and urine testing, serum immunoglobulins, EEG, ECG, chest and skull radiographs were all normal. Amino acid determinations by chromatography on ion exchange column in serum and urine showed no abnormalities. Karyotype was 46 XX. Serological tests for syphilis were negative. CSF tests for proteins, cells, glucose, gamma globulin and IgG were normal and VDRL was non-reactive. Motor and sensory conduction velocity of the median nerve, and electromyography of the abductor pollicis brevis and tibialis anterior muscles were normal. CT scan showed enlargement of the fourth ventricle and of the superior cerebellar, prepontine and cerebellopontine angle cisterns (fig (B)), and atrophy of the superior vermis (fig (C)). Applying the method of Koller $e t$ 


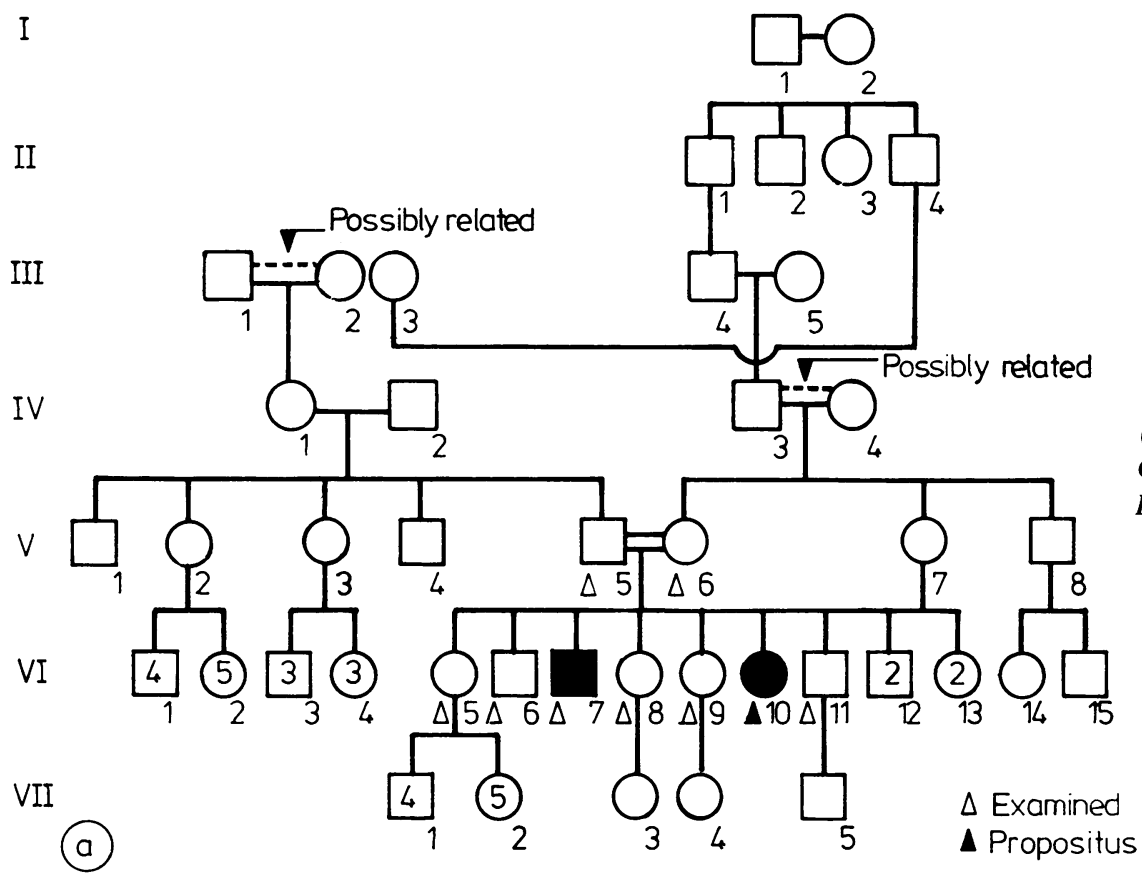

Fig (A) Family pedigree. $(B, C) C T$ scan of Case VI-10.

For details see text.

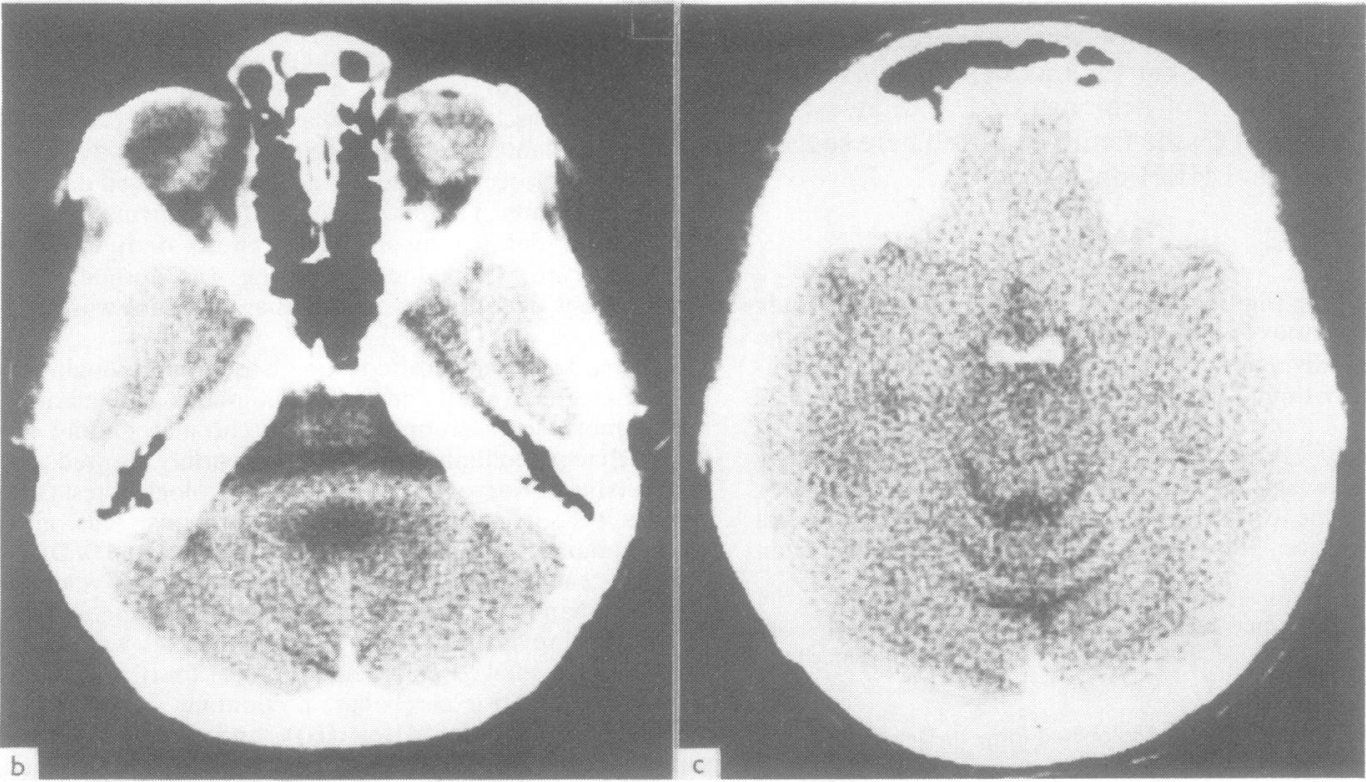


$a l,{ }^{7}$ the superior cistern ratio was $0 \cdot 15$, and the fourth ventricle ratio was $0 \cdot 12$; the cistern-brainstem ratio, although difficult to assess because of the artefact on the image (fig (B)), was estimated at a value not less than $0 \cdot 16$.

Case VI-7 A 39-year-old male who had been normal until the theoretical age of puberty, when only slight sexual development took place and lack of interest in the opposite sex became evident. He has never needed to shave. The neurological problems started in 1974 , at the age of 34 years, with behavioural disorders and intention tremor. He was assessed in the Neurosurgery Department of our hospital from 1975 onwards. Routine analyses, repeat EEGs and a carotid angiogram showed no abnormalities. In July 1979 , after the chance discovery of severe anaemia, he was diagnosed as having acute lymphoblastic leukaemia. Examination at this time revealed a patient with marked pallor of the skin and mucous membranes, and a eunuchoid habitus with a delicate skin, scant facial and axillary hair, female distribution of pubic hair, a small penis and small soft testes, but no gynaecomastia. Neurological examination showed a patient with advanced dementia, gross limb and axial ataxia, and scanning dysarthria. Muscle-stretch reflexes were normal, and plantar responses ambiguous. There was bilateral pes cavus, but no nystagmus, retinal degeneration or ophthalmoplegia. The patient did not cooperate in the testing of sensation, or of the first, second and eighth cranial nerves. CT scan could not be carried out. Karyotype was $46 \mathrm{XY}$. Haematology tests gave results characteristic of acute lymphoblastic leukaemia, with severe anaemia (haemoglobin $3.5 \mathrm{~g} / 100 \mathrm{ml}$ and haematocrit $7 \%$ ). The remainder of the complementary tests carried out in both brother and sister were normal.

Endocrinological studies The studies were done in case VI-10 two months after oral contraceptives were discontinued and in case VI-7 before beginning therapy for leukaemia. Basal levels of LH, FSH, prolactin and testosterone were obtained in cases V-5, VI-5, VI-6, VI-8, VI-9 and VI-11. Pituitary stimulation tests were done using TRH 400 mcg (Prem SA, Barcelona), LHRH $100 \mathrm{mcg}$
(Lufurán, UCB Laboratories, Barcelona) and crystalline insulin $0 \cdot 1 \mathrm{IU} / \mathrm{kg}$. Blood sugar fell from $5 \cdot 83$ to 2.5 and from $5 \cdot 5$ to $2 \cdot 1 \mathrm{mmol} / \mathrm{l}$ (in cases VI-7 and VI-10, respectively). After a baseline study, cases VI-7 and VI-10 were treated with LHRH $100 \mathrm{mcg}$ im, twice daily for five days and a second LHRH test was done in each case under similar conditions.

Hormone determinations were all done in duplicate, using commercial kits, previously standardised in our laboratory. Cortisol, serum $\mathrm{T}_{4}$ and $\mathrm{T}_{3}, \mathrm{~T}_{3}$-uptake index and TSH kits were obtained from Mallickrodt (Dietzenbach, Germany), HGH from Pharmacia Diagnostics AB (Uppsala, Sweden); FSH, LH and prolactin from Diagnostic Products Corporation (Los Angeles, CA, USA), and testosterone from Nordic Immunological Laboratories (Tilburg, The Netherlands). All samples were run in the same assay to avoid interassay variation.

\section{Results}

Cases V-5, VI-5, VI-6, VI-8, VI-9 and VI-11 showed normal values in all basal determinations. Results of the affected cases are shown in the table. Thyroxine values were normal. Triiodothyronine was $2.6 \mathrm{mmol}$ in case VI-10 and fell in case VI-7 $(0.78 \mathrm{mmol} / \mathrm{l})$ below the normal range. The $T_{3}$-resin uptake values were normal, indirectly showing a normal concentration of TBG. Basal levels of TSH, prolactin, $\mathrm{HGH}$ and cortisol were all normal in both cases. The response to pituitary stimulation with insulin-induced hypoglycaemia and with TRH showed a normal pattern of prolactin, $\mathrm{HGH}$ and TSH; cortisol response was normal in case VI-7 and suboptimal in case VI-10. Testosterone was low in case VI-7. Both cases showed low levels of basal LH and FSH, and these did not adequately increase after a first LHRH stimulation. However, after treatment for five days with LHRH the response to the same stimulus became normal in both cases.

Table Results of endocrine studies in affected cases

\begin{tabular}{|c|c|c|c|c|c|c|c|c|c|c|c|}
\hline & \multirow{3}{*}{$\begin{array}{l}\text { Thyroxine } \\
\text { (nmol/l) }\end{array}$} & \multirow{3}{*}{$\begin{array}{l}\text { Triiodo- } \\
\text { thyronin: } \\
\text { (nmol/l) }\end{array}$} & \multirow{3}{*}{$\begin{array}{l}\text { T3-resin } \\
\text { uptake } \\
(\%)\end{array}$} & \multicolumn{4}{|c|}{ TRH stimulation } & \multicolumn{4}{|c|}{ Insulin induced hypoglycaemia } \\
\hline & & & & \multicolumn{2}{|c|}{$\begin{array}{l}\text { TSH } \\
\text { unit/l) }\end{array}$} & \multicolumn{2}{|c|}{$P R L(u g / l)$} & \multicolumn{2}{|c|}{$H G H(u g / l)$} & \multicolumn{2}{|c|}{ Cortisol (umol/l) } \\
\hline & & & & basal & peak & basal & peak & basal & peak & basal & peak \\
\hline $\begin{array}{l}\text { Case VI-10 } \\
\text { Case VI-7 } \\
\text { Normal ranges }\end{array}$ & $\begin{array}{l}141 \\
77 \cdot 2 \\
51-141\end{array}$ & $\begin{array}{l}2 \cdot 6 \\
0.78 \\
1.8-3.5\end{array}$ & $\begin{array}{l}38 \\
40 \cdot 5 \\
34-46\end{array}$ & $\begin{array}{l}3 \cdot 4 \\
1 \\
1-5\end{array}$ & $\begin{array}{l}10 \\
12 \\
9-15\end{array}$ & $\begin{array}{l}5 \cdot 2 \\
8 \\
5-20\end{array}$ & $\begin{array}{l}42 \\
25 \\
25-45\end{array}$ & $\begin{array}{l}0.5 \\
0.5 \\
0.5\end{array}$ & $\begin{array}{r}25 \\
15 \\
>12\end{array}$ & $\begin{array}{l}0.38 \\
0.43 \\
0.15-0.70\end{array}$ & $\begin{array}{l}0.68 \\
0.81 \\
0.8-1.6\end{array}$ \\
\hline
\end{tabular}

\begin{tabular}{|c|c|c|c|c|c|c|c|c|c|}
\hline & \multicolumn{4}{|c|}{ First LHRH stimulation } & \multicolumn{4}{|c|}{ Second LHRH stimulation } & \multirow{2}{*}{$\begin{array}{l}\text { Testosterone } \\
\text { (umol/l) }\end{array}$} \\
\hline & \multicolumn{2}{|c|}{$\begin{array}{l}\text { FSH (int. unit/l) } \\
\text { basal peak }\end{array}$} & \multicolumn{2}{|c|}{$L H$ (int. unit/l) } & \multicolumn{2}{|c|}{ FSH (int. unit/l) } & $\begin{array}{l}\text { LH (ir } \\
\text { basal }\end{array}$ & $\begin{array}{l}\text { t/l) } \\
\text { peak }\end{array}$ & \\
\hline $\begin{array}{l}\text { Case VI-10 } \\
\text { Case VI-7 } \\
\text { Normal ranges }\end{array}$ & $\begin{array}{l}2 \\
2 \cdot 4 \\
3 \cdot 2-15\end{array}$ & $\overline{3}$ & $\begin{array}{l}2 \\
1 \\
5 \cdot 8-20\end{array}$ & $\overline{6 \cdot 8}$ & $\begin{array}{l}3 \cdot 5 \\
2 \cdot 6\end{array}$ & $\begin{array}{l}8 \cdot 6 \\
6\end{array}$ & $\begin{array}{l}9 \\
3 \cdot 7\end{array}$ & $\begin{array}{l}21 \cdot 5 \\
12 \cdot 2\end{array}$ & $\begin{array}{l}-3 \cdot 4 \\
10-33 \text { (male) }\end{array}$ \\
\hline
\end{tabular}

TRH denotes thyrotrophin-releasing hormone; TSH, thyroid-stimulating hormone; PRL, prolactin; HGH, human growth hormone. LHRH denotes luteinising hormone-releasing hormone; FSH, follicle-stimulating hormone; LH, luteinising hormone. 


\section{Discussion}

The clinical data of this family are consistent with those described in familial ataxia with hypogonadism. As with all the patients previously reported, cerebellar ataxia, axial and appendicular, with dysarthria were the main symptoms. Dementia, as in our second case, or mental subnormality often has been an outstanding feature. ${ }^{1358-10}$ Mild spinal symptoms such as those described here have been reported regularly. The following signs and symptoms, though absent in our cases, have been reported in others: dysphagia, ${ }^{8}$ nystagmus, ${ }^{2458}$ deafness, ${ }^{69}$ abnormal movements, ${ }^{8}$ and anosmia or strabismus. ${ }^{10}$ Transmission of the disorder has been considered to be X-linked, ${ }^{11}$ although the incidence of affected individuals in families with proved or presumed hypogonadotropic hypogonadism and ataxia is consistent with an autosomal recessive transmission. ${ }^{6}$ Conclusive evidence of an autosomal recessive transmission is found both in our pedigree and that of Neuhäuser and Opitz. ${ }^{5}$

The role of CT scanning in the diagnosis of cerebellar atrophy has been well established. ${ }^{72-15}$ The CT scan in our case showed atrophy of the cerebellum and brain stem, a combination which is suggestive of olivopontocerebellar atrophy. ${ }^{15}$ This type of cerebellar atrophy has not been reported previously in familial ataxia with hypogonadism. In fact, neuroradiological studies, either air encephalography or CT scan, are mentioned only in one of the patients described by Matthews and Rundle, ${ }^{3}$ in whom an air encephalogram showed no evidence of cerebral or cerebellar atrophy. On the other hand, postmortem examination in cases with proven hypogonadotropic hypogonadism revealed spinocerebello-olivary degeneration ${ }^{6}$ or a complex spino-olivo-dentate abiotrophy affecting various structures of the brain stem, axonal neuropathy and degeneration of the spiral ganglion cells. ${ }^{9}$

The endocrinological studies carried out on our two patients demonstrated the existence of hypogonadotropic hypogonadism. As in Case 1 of Lowenthal et al, ${ }^{10}$ after the first stimulation with LHRH the gonadotropins did not alter. However, after repetitive stimulation with LHRH, we achieved an obvious increase in gonadotropins. This increase in gonadotropins after repetitive stimulation indicates that the hypogonadism was due, not to the inability of the pituitary to secrete gonadotropins, but to the absence of stimulation by the hypothalamic stimulating factor. ${ }^{16}$ The cortisol response to hypoglycaemia was suboptimal despite an appropriate fall in blood sugar, which prompted an adequate response of HGH. The remainder of the hypothalamic-pituitary axis was normal which also suggests, as Bernard-Weil and Endtz ${ }^{1}$ pointed out, a primary hypothalamic dysfunction. Contrary to what was expected from these data, postmortem examinations have not demonstrated hypothalamic lesions. ${ }^{69}$ Nevertheless, biochemical defects in normal histological structures have been demonstrated in cases of multiple system atrophy. ${ }^{17} \mathrm{~A}$ biochemical defect of the tuberoinfundibular neurons therefore seems to be a possible explanation for hypogonadotropic hypogonadism. In case VI-7 a decrease in the levels of $T_{3}$ with normal $T_{4}$ and TSH was demonstrated, all of which is suggestive of an "euthyroid low $T_{3}$ syndrome" 18 associated with his acute leukaemia. The increases in the blood levels of glutamine and alanine, and in the urine levels of glutamine and ornithine alanine reported by Lowenthal $e t a l^{10}$ were not found in our patients.

\section{References}

${ }^{1}$ Bernard-Weil E, Endtz LJ. Sur un cas familial de dégénération spino-cérébelleuse avec eunuchoïdisme hypogonadotrophique. Considérations pathogéniques et méthodologiques. Nouv Press Med 1962;70:524-6.

${ }^{2}$ Volpé R, Metzler WS, Johnston MW. Familial hypogonadotropic eunuchoïdism with cerebellar ataxia. J Clin Endocrinol 1963;23:107-15.

${ }^{3}$ Matthews WB, Rundle AT. Familial cerebellar ataxia and hypogonadism. Brain 1964;87:463-8.

4 Boucher BJ, Gibberd FB. Familial ataxia, hypogonadism and retinal degeneration. Acta Neurol Scand 1969;45:507-10.

${ }^{5}$ Neuhäuser G, Opitz JM. Autosomal recessive syndrome of cerebellar ataxia and hypogonadotropic hypogonadism. Clin Genet 1975;7:426-34.

- Howell DA, Matthews WB. Cerebellar ataxia and hypogonadism. In: Vinken PJ and Bruyn GW, eds. Handbook of Clinical Neurology (Vol 21, part 1). Amsterdam: North Holland Publishing Company, 1975:467-76.

${ }^{7}$ Koller WC, Glatt SL, Perlik S, Huckman MS, Fox JH. Cerebellar atrophy demonstrated by computed tomography. Neurology (NY) 1981;31:405-12.

${ }^{8}$ Altschul R, Kotlowski K. Pallido-cerebello-olivary degeneration with eunuchoidism. J Nerv Ment Dis 1956;123:112-6.

9 Sylvester PE. Spino-cerebellar degeneration, hormonal disorder, deaf mutism and mental deficiency. $J$ Ment Defic Res 1972;16:203-14.

${ }^{10}$ Lowenthal A, Bekaert J, Van Dessel F, Van Hauwaert J. Familial cerebellar ataxia with hypogonadism. $J$ Neurol 1979;222:75-80.

${ }^{11}$ Mckussick VA. Mendelian Inheritance in Man. Baltimore: Johns Hopkins Press, 1971:373-4.

12 Lee SH, Altamirano LS, Toglia JU. Cerebellar atrophy: Pneumoencephalography and computerized tomography correlation. Neuroradiology 1978;16:179-80.

${ }^{13}$ Syldensted C, Pedersen L. Computed tomography in hereditary ataxias. Neuroradiology 1978;16:327-8. 
${ }^{14}$ Rothman SLG, Glanz S. Cerebellar atrophy: The differential diagnosis by computerised tomography. Neuroradiology 1978;16:123-6.

15 Allen JH, True Martin J, Mclain WL. Computed tomography in cerebellar atrophic processes. Radiology 1979;130:379-82.

${ }^{16}$ Snyder PJ, Rudenstein RS, Gardner DF, Rothman JG. Repetitive infusion of gonadotropin-releasing hormone distinguishes hypothalamic from pituitary hypo- gonadism. J Clin Endocrinol Metab 1979;48:864-8.

${ }^{17}$ Spokes EGS, Bannister R, Oppenneimer DR. Multiple system atrophy with autonomic failure. Clinical, histological and neurochemical observations on four cases. J Neurol Sci 1979;43:59-82.

${ }^{18}$ Bermúdez F, Surks MI, Oppenheimer JH. High incidence of decreased serum tri-iodothyronine concentration in patients with non-thyroidal disease. $J$ Clin Endocrinol Metab 1975;41:27-40. 


\section{Notice}

\section{Behavioral Neurology Society Formed}

The Behavioral Neurology Society has recently been formed. The purpose of the Society is to foster communication among individuals and disciplines contributing to service, education and research in behavioral neurology and to promote interest in brain-behavior relationships Membership is open to physicians (Regular Members) who are actively interested in behavioral neurology and to other professionals and persons in training (Associate Membership) who devote a major portion of their activity to behavioral neurology or closely allied fields. An annual meeting will be held in conjunction with the American Academy of Neurology and there will be a quarterly newsletter. Interested individuals should contact the Society Secretary: Francois Boller, MD., PhD., Department of Neurology, 322 Scaite Hall, University of Pittsburgh, Pittsburgh PA 15261, USA

Correction. In the paper "Familial cerebellar ataxia and hypogonadotropic hypogonadism: evidence for hypothalamic LHRH deficiency" (J Neur Neurosurg Psychiatry 1982; 45: 747-51) fig (A) was incorrect. The correct figure is reproduced below.

II

III

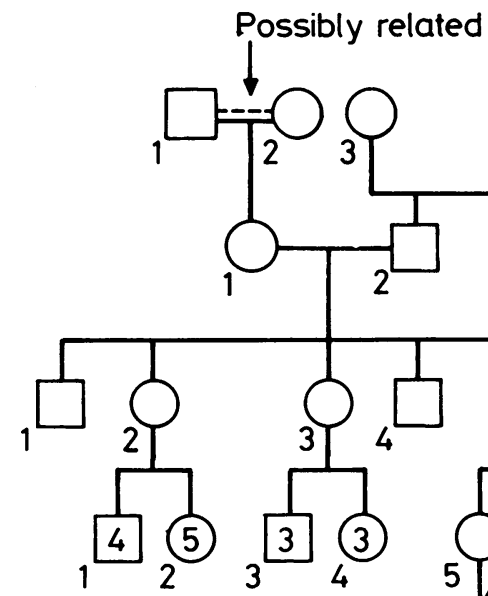

IV

VII

I

V

VI

4 2 3

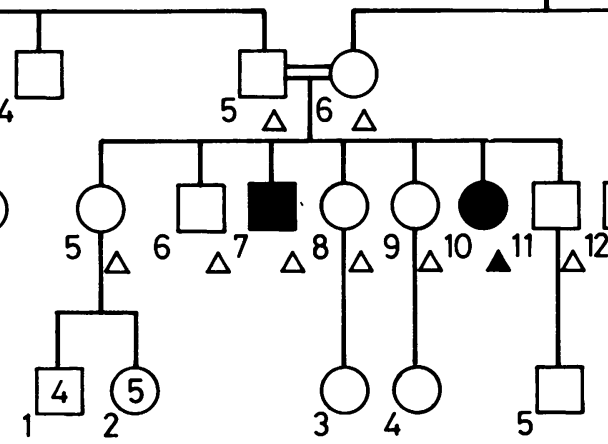<smiles>CC1CCCCC1</smiles>

7<smiles>CCC([O])CC</smiles><smiles>c1ccccc1</smiles>
1314

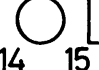

Examined $\triangle$

Propositus

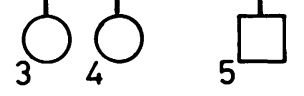

